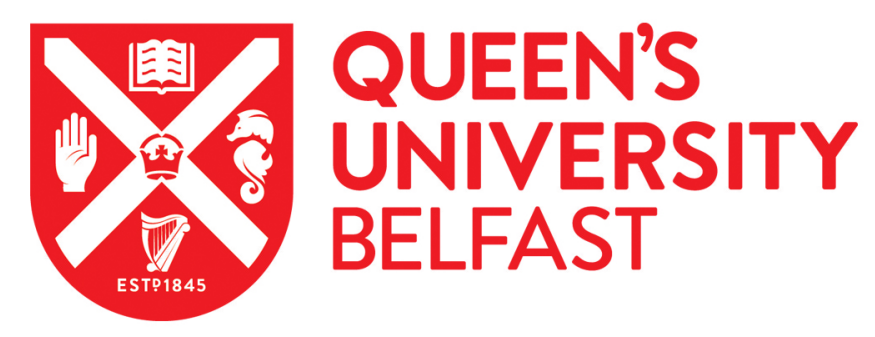

\title{
Depression interventions for individuals with coronary artery disease - Cost-effectiveness calculations from an Irish perspective
}

\begin{abstract}
Jabakhanji, S. B., Sorensen, J., Carney, R. M., Dickens, C., Dempster, M., Gallagher, J., Caramlau, I., \& Doyle, F. (2022). Depression interventions for individuals with coronary artery disease - Cost-effectiveness calculations from an Irish perspective. Journal of Psychosomatic Research, 155, [110747].
\end{abstract}

https://doi.org/10.1016/j.jpsychores.2022.110747

Published in:

Journal of Psychosomatic Research

Document Version:

Peer reviewed version

Queen's University Belfast - Research Portal:

Link to publication record in Queen's University Belfast Research Portal

\section{Publisher rights}

Copyright 2022 Elsevier

This manuscript is distributed under a Creative Commons Attribution-NonCommercial-NoDerivs License

(https://creativecommons.org/licenses/by-nc-nd/4.0/), which permits distribution and reproduction for non-commercial purposes, provided the author and source are cited.

\section{General rights}

Copyright for the publications made accessible via the Queen's University Belfast Research Portal is retained by the author(s) and / or other copyright owners and it is a condition of accessing these publications that users recognise and abide by the legal requirements associated with these rights.

Take down policy

The Research Portal is Queen's institutional repository that provides access to Queen's research output. Every effort has been made to ensure that content in the Research Portal does not infringe any person's rights, or applicable UK laws. If you discover content in the Research Portal that you believe breaches copyright or violates any law, please contact openaccess@qub.ac.uk. 


\section{Title page}

Title: Cost-effectiveness of depression interventions for individuals with coronary artery disease in Ireland

Short running head: Cost-effectiveness of depression interventions

\section{Authors and affiliations:}

Samira Barbara Jabakhanji, PhD, Healthcare Outcomes Research Centre, RCSI University of Medicine and Health Sciences, Dublin, Ireland

Jan Sorensen, MSc, Healthcare Outcomes Research Centre, RCSI University of Medicine and Health Sciences, Dublin, Ireland

Robert M. Carney, PhD, Department of Psychiatry, Washington University School of Medicine, St Louis, MO, USA

Chris Dickens, PhD, College of Medicine and Health, University of Exeter, Exeter, United Kingdom Martin Dempster, PhD, School of Psychology, Queen's University Belfast, Northern Ireland Jonathan Gallagher, MPSychSc, Department of Cardiology, Beaumont Hospital, Dublin, Ireland Isabela Caramlau, PhD, DClinPsy, Department of Psychology, Beaumont Hospital, Dublin, Ireland Frank Doyle, PhD, Department of Health Psychology, RCSI University of Medicine and Health Sciences, Dublin, Ireland 


\section{Corresponding author:}

Samira Barbara Jabakhanji

Healthcare Outcomes Research Centre

RCSI University of Medicine and Health Sciences

123 St Stephen's Green

Dublin 2, Ireland

P: 00353897005396

Fax: N/A

E: samirajabakhanji@rcsi.ie 


\begin{abstract}
Background: Up to $40 \%$ of individuals with coronary artery disease experience moderate or severe acute depression requiring targeted treatment. We assessed the cost-effectiveness of four interventions for depression in individuals with coronary artery disease.

Methods: We assessed the cost-effectiveness of pharmacotherapy, psychotherapy, collaborative care and exercise, using estimates from a published network meta-analysis. Effectiveness was measured as remission rate after 8 and 26 weeks. The cost assessment included standard doses of antidepressants, contact frequency, and staff time per contact. Unit costs were calculated as health services' purchase price for pharmaceuticals and mid-point staff salaries obtained from the Irish Health Service Executive and validated by clinical staff. Incremental cost-effectiveness ratio was calculated as the incremental costs over incremental remissions compared to usual care. High- and low-cost scenarios and sensitivity analysis were modelled by changing contact frequencies, and assuming individual vs. group psychotherapy or exercise.
\end{abstract}

Results: After 8 weeks, the estimated incremental cost-effectiveness ratio was lowest for group exercise (€526 per remission), followed by pharmacotherapy (€589), individual psychotherapy (€3117) and collaborative care (€4964). After 26 weeks, pharmacotherapy was more cost-effective (€591) than collaborative care (€7203) and individual psychotherapy (€9387); no 26-week assessment for exercise was possible. Sensitivity analysis showed that group psychotherapy could be most cost-effective after 8 weeks (€519) and cost-effective after 26 weeks (€1565); however no trials investigated its effectiveness.

Discussion: Large variation in incremental cost-effectiveness ratios was seen. With the available data, the most cost-effective depression intervention for individuals with coronary artery disease after 8 weeks was group exercise.

\title{
Keywords:
}

coronary artery disease, cost-effectiveness, depression, Ireland, psychosocial intervention; exercise therapy 


$\begin{array}{ll}\text { Abbreviations: } \\ \text { CAD } \quad \text { Coronary artery disease } \\ \text { CBT } \quad \text { Cognitive behavioural therapy } \\ \text { GP } \quad \text { General practitioner } \\ \text { HCS } \quad \text { High-cost scenario } \\ \text { HSE } \quad \text { Health Service Executive } \\ \text { ICER } \quad \text { Incremental cost-effectiveness ratio } \\ \text { LCS } & \text { Low-cost scenario } \\ \text { MCS } & \text { Main cost scenario } \\ \text { n } & \text { Number } \\ \text { NMA } & \text { Network meta-analysis } \\ \text { RCT } & \text { Randomised controlled trial } \\ \text { SD } & \text { Standard deviation } \\ & \end{array}$




\section{Introduction}

Coronary artery disease (CAD) is the leading cause of death and years of life lost, the second leading cause of disability-adjusted life years, and affected nearly 200 million adults globally in $2019^{1}$, with many patients also experiencing elevated depressive symptoms or major depression. For example, after myocardial infarction, $20 \%$ of individuals are diagnosed with major depressive disorder, and up to $38 \%$ have elevated symptoms ${ }^{2}$. In Ireland, $43 \%$ of adults aged 50 years or older report a history of cardiovascular diseases, and $40 \%$ report either moderate $(28 \%)$ or severe $(12 \%)$ acute depression ${ }^{3}$. Depression has been linked to poorer health outcomes in individuals with CAD, including higher mortality, morbidity, poorer quality of life and elevated health service utilisation when compared to individuals with CAD without depression ${ }^{4}$.

Due to the high prevalence of post-CAD depression and associated long-term costs to personal health, wellbeing, daily functioning, and health systems, cardiac service guidelines promote effective depression management. Nevertheless, cardiac management tends to be the primary concern and medication for secondary prevention often remains the only response to CAD episodes. Notably, while a high number of evidence-based depression interventions are available, these may not always be suitable for cardiac patients due to patient preference, concerns about patient safety, such as drug interactions, or a lack of CAD specialisation among intervention providers.

A number of previous studies have investigated the effectiveness of various depression interventions in the CAD population specifically ${ }^{5,6}$, including a recent in-depth network meta-analysis (NMA) by Doyle et $\mathrm{al}^{7,8}$. The NMA compares exercise, psychotherapy (if underpinned by theory and delivered by trained therapists), antidepressants, collaborative care (interventions including a multi-professional approach, structured management plan, scheduled follow-up and enhanced inter-professional communication ${ }^{9}$ ) and combined psychotherapy and antidepressant interventions. When investigating treatment effects at 8 weeks post treatment initiation, Doyle et al ${ }^{7}$ found the most robust evidence base for antidepressants, strongest effects for exercise, and effectiveness of psychotherapy and collaborative care compared to usual care.

In addition to effectiveness, policymakers need to consider the country-specific cost of each intervention for health system planning, raising the needed for health economic assessments. The costeffectiveness of these interventions has previously been assessed in other patient populations 
internationally, including individuals with dementia ${ }^{10}$, heart failure ${ }^{11}$, cancer ${ }^{12}$, chronic pain ${ }^{13}$, postnatal depression ${ }^{14,15}$, social anxiety ${ }^{16}$ and multiple chronic morbidity ${ }^{17}$. A comprehensive costeffectiveness analysis of depression interventions in individuals with CAD is currently missing ${ }^{7}$. Accordingly, the aim of this study was to identify the most cost-effective intervention for depression in individuals with CAD from an Irish perspective. To achieve this, we build on recent evidence from an indepth NMA that investigates the effectiveness of antidepressant use, psychotherapy, collaborative care and exercise treatment in individuals with CAD. 


\section{Materials and methods}

We conducted a cost-effectiveness analysis of four depression interventions for individuals with CAD. Specifically, we assessed the cost-effectiveness of pharmacotherapy, psychotherapy, collaborative care, and exercise treatment and used a micro-costing approach to cost the interventions in the Irish context. CHEERS guidelines for reporting were used ${ }^{18}$. As measure of effectiveness we used the number needed to treat to achieve remission after 8 and 26 weeks of intervention.

\section{Data}

We obtained data on treatment effectiveness (i.e. proportion achieving remission) from a recently published NMA ${ }^{7}$. The NMA included 15 pharmacotherapy, 15 psychotherapy, 4 collaborative care and 1 exercise trial published in 1982-2020, most of which had been conducted in international hospital outpatient settings. Studies were excluded that did not report effectiveness after 8 weeks, 26 weeks or both. One combined psychotherapy and antidepressant intervention was also included, which we did not consider in our study due to a high risk of bias. Randomised controlled trials (RCTs) were included if $\geq 70 \%$ of participants had a history of acute CAD, including acute coronary syndrome, angina or angiographically confirmed coronary disease, which had been treated with percutaneous coronary intervention or coronary bypass graft. Participants furthermore scored above threshold on a validated depression scale or had clinically-diagnosed depression, and they had a depression score recorded at baseline and post-intervention. Comparison groups received one of three interventions: 1) placebo treatment (pharmacotherapy RCTs), 2) no treatment, waitlist or treatment as usual, or 3) treatment control. Participant age ranged from 52 to 65 years and one third were women. Data were available for each of the interventions at 8 and 26 weeks post treatment initiation, except exercise, which was only evaluated after 8 weeks. All interventions included here were more effective than usual care at 8 weeks (pharmacotherapy, psychotherapy, exercise) and/or 26 weeks (pharmacotherapy, psychotherapy, collaborative care). Acceptability of received interventions was evaluated in the NMA measuring dropout rates and deemed comparable. Details of the NMA and included trials were described elsewhere ${ }^{7,8}$. For comparability of the interventions, we used the standardised mean difference of each intervention compared against usual care that was published in the NMA ${ }^{7}$. 
Using the activity-based costing approach ${ }^{17,19}$, we developed process maps for of each intervention using the information included in the NMA. We mapped all weekly healthcare activities that were part of an intervention. This gave us an overview of the weekly use of resources during the intervention period. Specifically, from the same trials, we identified the type and professional level of staff that was needed for each activity, the time per staff and activity, as well as type and daily dosage of medication where appropriate. We accumulated the weekly staff time and medication use for 8 weeks, weeks 9 to 26 and the total 26-week treatment periods.

In order to cost the resource use and treatment costs over time, we used standardised 2019-€ unit cost data from Ireland. Irish salary scales from the Health Service Executive (HSE) provided annual salaries for each type and experience level (by years) of healthcare professionals employed in Ireland ${ }^{20}$. In Ireland, all public health services operate under public service regulations and are managed under the HSE Code of Governance through the HSE organisational structure ${ }^{21}$. The latest salary scales had been published with effect from $1^{\text {st }}$ October 2018, $1^{\text {st }}$ January 2019 and $1^{\text {st }}$ September $2019^{20}$. We used mid-points of the most recent relevant salaries from September 2019; however there was little variation across these three salary scales. Information on paid leave was retrieved from the Department of Public Expenditure and Reform. This includes standard work days per year (i.e. accounting for annual leave and public holidays) and mean sick leave for public services in the healthcare sector in 2018. These 2019-data were unavailable; however trends from 2013 to 2018 show that there is little variation in sick leave among Irish healthcare services ${ }^{22,23}$. Information on standard doses, packaging sizes and Irish reference prices of antidepressants was retrieved from an Irish pharmacy technician.

\section{Data validation}

As some of the data informing the process maps were from outside Ireland and stretching across nearly four decades, we reviewed Irish guidelines and asked three clinical psychologists/psychiatrists from the UK, USA and Ireland to validate the assumptions. This provided us with an up-to-date impression of patient care paths as they are commonly provided by the Irish healthcare system.

For additional validation, we used psychologist allowances (typically granted for 3-hour counselling sessions) published by the $\mathrm{HSE}^{20}$, and hourly costs of supervised exercise and psychologist counselling published in a recent Irish study ${ }^{24}$. 


\section{Assumptions}

The following assumptions were made for the four interventions studied. Depending on the variation in resources and activities considered possible for each intervention, a different number of cost scenarios were analysed for each of the four interventions, with the most realistic assumptions informing our main analysis and potential alternatives presented in additional cost scenarios. Details of the care pathways are provided in Appendices 1-4. Based on averages from Irish and international literature and upon validation by clinical staff, practical staff capacity available for patient care was assumed to be $65 \%$ for all staff ${ }^{25-28}$. While theoretical capacity includes all work hours excluding sick days and paid leave, but including training time and breaks, practical capacity refers to the proportion available for service delivery. Specifically, we define practical staff capacity to exclude sick leave, paid leave, breaks, education and training, and administrative tasks, and to include only contact time with patients or time liaising with colleagues about patient care, similar to Nguyen, Sammer ${ }^{29}$.

\section{Pharmacotherapy}

The analysis was performed for the HSE preferred drug for cardiac patients, Citalopram, assuming a mean dose of 33.1mg (SD 10.82) at last visit ${ }^{30,31}$, which was rounded to the nearest available dosage of 40mg (available in 28-day supplies). Sensitivity analysis was performed for the most prescribed drug in Ireland, Sertraline 50mg (assuming median: 50; IQR: 50, $100^{32}$ ), and the highly effective Escitalopram 10mg (assuming mean: 7.6; SD: $3.7^{33}$ ).

Staff costs were included for a total of 13 (main case scenario [MCS]), 6 (low cost scenario [LCS]) or 9 (high cost scenarios [HCS]) 15-minute consultations with a consultant (general practitioner (GP)) whenever prescriptions were issued (MCS: $n=5$; LCS: $n=5 ; H C S: n=7$ ) or a clinical nurse manager 1 (4 years experience) when no prescription was needed (MCS: $n=8 ;$ LCS: $n=1 ; H C S: n=2$ ). While the MCS includes a higher total number of consultations, the HCS is more expensive due to the larger number of GP consultations. Moreover, the LCS assumes that most consultations are needed within the first 8 weeks of treatment, after which only brief follow-up is assumed (Appendix 1).

\section{Psychotherapy}


Based on Irish standards, 8 individual 60 -minute sessions of psychotherapy with a psychologist (5 years of experience) were assumed. Of these, 6 sessions take place within the first 8 weeks of treatment (MCS) ${ }^{30,31,33-36}$. The HCS includes 11 psychotherapy sessions per patient of which 7 within the first 8 weeks (HCS) ${ }^{34}$. In exploratory sensitivity analyses, we assumed 8 group therapy sessions instead of individual therapy, as the effects of group therapy are similar to individual therapy ${ }^{37}$, with a group size of 6 patients per session (LCS) (Appendix 2).

\section{Collaborative care}

Based on the experience from clinical psychology, we assume that $40 \%$ of patients choose antidepressant treatment, $40 \%$ psychotherapy and $20 \%$ watchful waiting. While $2 / 3$ of antidepressant and psychotherapy patients maintain on their respective paths, we assume the remaining $1 / 3$ require treatment adjustment at week 8 . Of those requiring treatment adjustment, again $1 / 3$ is assumed to require a second adjustment at week $14^{38-40}$. The respective paths of patients by initial choice and treatment progression are detailed in Appendix 3.

In summary, all patients initially have a 15-minute-long consultation with a psychologist, consultant (GP) and staff nurse to discuss treatment options and decide which path to choose. After this, the number of visits to a staff nurse or GP differs by treatment path, where either visit is assumed to take 15 minutes on average. CBT sessions with a psychologist, where needed, are assumed to take 60 minutes.

Furthermore, patient progress is discussed in review meetings that take place between a staff nurse, a GP, a psychologist and a psychiatrist every two weeks. It is assumed that the review requires 10 minutes per patient, and that patient progress is only reviewed until their treatment has been deemed successful (i.e. for 8 weeks, 14 weeks or the full 26 weeks). Irrespective of their initial treatment path, patients with treatment success after 8 weeks accordingly need to be reviewed 4 times, those with 1 adjustment (i.e. success after 14 weeks) 7 times and those with two adjustments require 13 reviews. Patients in the watchful waiting group are assumed to be reviewed once (Appendix 3 ).

\section{Exercise}

We assumed supervised graded treadmill exercise testing with a nurse and a cardiac physiologist (15 minutes) at the outset, followed by 3 supervised 60-minute sessions of treadmill exercise per week over 
the course of 16 weeks. Exercise sessions were assumed to be supervised by one cardiac physiologist with five years of work experience ${ }^{32}$. In line with Irish cardiac rehabilitation guidelines ${ }^{41}$, we assumed group exercise sessions with a 5:1 patient-staff ratio (LCS); however we also calculated costs for a 1:1 ratio (HCS) in sensitivity analysis (Appendix 4).

\section{Unit costs}

Unit costs used for analysis in this study are detailed in the Appendix 5.

\section{Analysis}

We calculated the incremental cost per patient in remission for each intervention from the perspective of Irish healthcare. In addition to our MCSs, we modelled LCSs and HCSs with varying numbers of consultations, or different antidepressants, to account for variations in resource use between patients. Furthermore, we explored scenario variations with individual vs. group psychotherapy for sensitivity analysis, as the effects of group psychotherapy was previously found equivalent to individual psychotherapy ${ }^{37}$. Similarly, we explored individual vs. group exercise in sensitivity analysis.

For each intervention, we estimated the number needed to treat by transforming Cohen's D estimates

42. We then multiplied treatment cost by the number needed to treat to retrieve the cost per patient with post-treatment remission. The analyses were performed for every scenario investigating costeffectiveness separately for the first 8 weeks, and for the total duration of 26 weeks. 


\section{Results}

\section{Costs}

Table 2 shows the cost of each intervention per patient for 8 weeks, weeks 9-26 and the total 26 weeks. For all interventions, the majority of costs occurred in the first 8 weeks of treatment.

Within the first 8 weeks, group exercise was the cheapest intervention (€201.65), closely followed by pharmacotherapy (€215.66). In fact, pharmacotherapy was cheaper in the LCS and HCS (Table 2). Individual psychotherapy (€448.43) and collaborative care (€501.43) were more expensive.

Costs to extend the interventions from 9 to up to 26 weeks were relatively low, ranging from $€ 120$ (pharmacotherapy) to $€ 327$ (collaborative care).

Over the full 26 weeks, pharmacotherapy was cheapest in our MCS (€335.88), as well as in the LCS (€251.62) and HCS (€377.46). In general, choice of antidepressant did not impact intervention costs much if consultation frequency and duration remained unchanged (see Appendix Table A6). Group exercise was the second-cheapest intervention (€385.58). The cost of individual psychotherapy was higher (€597.91) and highest for collaborative care (€828.91). Both individual psychotherapy and collaborative care cost just under $€ 1,000$ per patient in the HCSs.

\section{Sensitivity analyses}

Sensitivity analysis showed that group psychotherapy would be the cheapest intervention per patient at $8(€ 74.74)$ and the full 26 weeks (€99.65). Individual exercise would exceed the cost of all interventions, incurring costs of $€ 1,857.05$ in total.

$\ll<<<A B L E 1$ HERE $\gg \gg>$ 


\section{Cost-effectiveness}

Incremental cost-effectiveness ratios (ICERs) are presented in Table 3, indicating the cost per patient in remission. After 8 weeks, using the main assumptions, the estimated ICER was lowest for group exercise (€526.30) and pharmacotherapy (€750.50) and highest for collaborative care (€5556.13). Individual psychotherapy (€3116.58) ranged in the middle. Scenario analysis indicated that pharmacotherapy therapy costs by remission might be reduced to $€ 589.25$ even in the HCS, whereas costs in the HCS were higher for psychotherapy (€4210.53) and collaborative care (€5821.87).

After 26 weeks, the ICERs were $€ 591.15$ for pharmacotherapy, $€ 7203.19$ for collaborative care and $€ 9387.12$ for individual psychotherapy, while no 26-week assessment for exercise was possible as the only RCT included finished after 16 weeks. Scenario analysis showed relatively small variation across potential ICER estimates for pharmacotherapy (€442.84-664.33), whereas the ICER of individual psychotherapy might increase to almost $€ 15,000$.

\section{Sensitivity analysis}

In comparison, in our sensitivity analysis, the ICER of group psychotherapy was much lower (8 weeks: $€ 519.43$; 26 weeks: €1564.52), whereas it was higher for individual exercise (€2446.57 at 8 weeks), compared to group exercise in the main analysis.

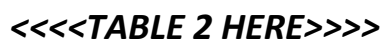




\section{Discussion}

\section{Main findings}

We conducted an analysis of the costs and cost-effectiveness of pharmacotherapy, psychotherapy, collaborative care and exercise to treat depression in individuals with CAD, studying main, low and high cost scenarios and performing sensitivity analysis.

Within an 8-week analytical perspective, group exercise was the cheapest and most cost-effective intervention, closely followed by pharmacotherapy, whereas psychotherapy and collaborative care were more costly and less cost-effective. Specifically, our cost scenarios showed that group exercise or pharmacotherapy with sertraline, citalopram or escitalopram could be delivered at around $€ 200$ per patient, whereas per-patient-costs for individual psychotherapy or collaborative care ranged between $€ 450$ and $€ 600$. Taking into account the number of patients needed to treat for each case of remission (i.e. efficacy), compared to usual care, incremental cost by remission after 8 weeks was $€ 526$ for group exercise, $€ 589$ to $€ 751$ for pharmacotherapy, $€ 3117$ to $€ 4211$ for individual psychotherapy, and €4964 to $€ 5822$ for collaborative care. As group exercise also was most effective after 8 weeks ${ }^{7}$, this appears the best option to treat depression in individuals with CAD.

Extending the treatment period of the four interventions to up to 26 weeks involved lower costs in weeks 9 to 26 in almost all scenarios studied compared to the cost occurring in the first 8 weeks; nevertheless, most treatments were not more cost-effective after 26 weeks. Only pharmacotherapy costs by remission decreased slightly, to between $€ 443$ and $€ 591$. Individual psychotherapy was least cost-effective after 26 weeks. Its cost by remission tripled and it nearly doubled for collaborative care, while no assessment for exercise after 26 weeks was possible. These findings suggest that very costeffective depression treatment can already be delivered within 8 weeks, whereas much more extensive treatment duration is only cost-effective in patients receiving pharmacotherapy.

While aimed at prevention of CAD and depression, as opposed to treatment, results from the EuroFIT trial confirm the low cost of group exercise interventions and point to their potential as a cost-effective long-term health strategy. Notably, costs for group exercise with added educational components delivered over 12 weeks in EuroFIT were much cheaper than in this study; however EuroFIT involved half the exercise dose (90 minutes per week) and three times the group size (15-20 adults) compared to our scenario ${ }^{43}$. Those increased group sizes may not be suitable to the CAD population for whom a higher 
level of supervision in smaller groups and higher exercise dose appears safer ${ }^{44}$ and opens opportunities for individualised exercise prescription.

Prior research confirms the relatively high treatment costs of collaborative care which were comparable in individuals with cancer ${ }^{12}$ and after acute coronary syndrome ${ }^{45}$, acute cardiac illness ${ }^{46}$ or coronary artery bypass graft (telephone-delivered) ${ }^{47}$. Costs were lower in individuals with diabetes and coronary diseases in one trial ${ }^{48}$. While economic outcome measures in these studies are not comparable to our study, the various trials identified collaborative care as likely cost-effective despite the higher implied costs compared to usual care ${ }^{46-48}$.

\section{Sensitivity analysis}

In addition to these scenarios, we explore in sensitivity analysis whether variations in delivery could lower costs further. We note that no trials were available that study the effectiveness of these intervention variations in individuals with CAD.

Results showed that, in our hypothetical scenario, group psychotherapy would involve lower costs at 8 weeks (€74) and 26 weeks ( $€ 100)$ than any other intervention studied, and that it holds potential to be the most cost-effective intervention after 8 weeks. Other studies indicate much higher costs for group psychotherapy in patients with social anxiety ${ }^{16}$ or postnatal depression ${ }^{15}$; however at higher intervention intensity (number and duration of sessions and staff requirements). Proportional costs at comparable intervention intensity would equate to about $€ 200$ after 26 weeks ${ }^{16}$. Unfortunately, no group psychotherapy trials were available that studied (cost-)effectiveness in individuals with CAD. Currently, group psychotherapy is not commonly offered to individuals with elevated depressive symptoms in Ireland. Accordingly, we assumed the same acceptability and effectiveness as in individual therapy ${ }^{37}$. Costs may potentially be lowered even further if group size is increased in line with CBT guidelines.

In turn, individual exercise in our sensitivity analysis was more expensive than any other treatment. A previous study identified similar costs in a 12-week-long centre-based exercise programme for cardiac patients ${ }^{49}$. While no trial on individual exercise effects on depression were available, this is unlikely more cost-effective than group exercise or pharmacotherapy. However, upon feasibility study in individuals with depression, individual home-based, tele-monitored exercise may be a cost-effective alternative to group exercise ${ }^{49}$. 
Future trials should investigate the feasibility, effectiveness, cost-effectiveness and ideal group size of group psychotherapy for individuals with CAD as we hypothesise that this could be a cost-effective alternative or addition to group exercise or pharmacotherapy in Ireland; however data to support this are missing.

\section{Implications}

Overall, these findings suggest that group exercise should be offered to individuals with CAD who experience depression, and that pharmacotherapy could be a cost-effective addition or replacement treatment for patients not responding to those treatments within 8 weeks. (Group) psychotherapy may benefit sub-groups of patients, especially if paired with other physical or mental health co-morbidities or risk factors.

As these care models already are in place in Ireland and likely require no implementation cost, group exercise, pharmacotherapy and (group) psychotherapy could each be offered individually to individuals with CAD and depression. In contrast, collaborative care is not currently available in Ireland and implementation costs would need to be considered in addition to the relatively high treatment costs identified in this study. As various other chronic disease management programmes have been implemented nationally ${ }^{50}$, implementation of collaborative care also appears feasible; given the better cost-effectiveness of other interventions, however, implementation in this context may not be worthwhile. Nevertheless, treatment as usual can be variable and access to various depression and CAD treatments at different points of care may increase quality and reduce administrative costs, waiting lists and travel time for patients. Also outside the collaborative care model, patients could thus access multiple cost-effective treatments (e.g. exercise and pharmacotherapy) simultaneously if deemed appropriate by treating clinicians.

Due to its benefits on cardiac outcomes, exercise is often included in cardiac rehabilitation, including in Ireland ${ }^{51,52}$, and patients may benefit from further inclusion of group psychotherapy and pharmacotherapy within cardiac rehabilitation services ${ }^{53}$. In Ireland, 8- to 10-week-long cardiac rehabilitation programmes offer group support and supervised exercise to patients as secondary and tertiary prevention; however the uptake in the cardiac population is low ${ }^{54}$ and coverage of cardiac physiologists in these services limited. Exercise provision through physiotherapists, or sports scientist, may increase resource availability in line with cardiac rehabilitation guidelines and at no additional cost 
${ }^{20,51}$. Incentivising greater use of these services and integrating group psychotherapy and pharmacotherapy alongside exercise within them may facilitate timely treatment and continuity of care.

Additional research needs to investigate the sustainability of interventions and their effectiveness beyond 6 months. Accordingly, in addition to the healthcare perspective presented, future cost studies should take a holistic societal perspective when investigating depression interventions, including resilience and lasting cardiovascular health. Moreover, alternative or multicomponent exercise programmes, differences between exercise in the context of a trial and patients' lives outside clinical settings, and costs of not treating depression in individuals with CAD, should be considered for study in the future.

\section{Strengths}

This study contributes to current literature on treatment outcomes by adding the dimension of cost and cost-effectiveness. One major strength is the use of trial data included in a recently published NMA, which is based on rigorous analysis of the literature. Accordingly, included studies were assessed for bias and methodological quality, and, despite differences in intervention details, comparability of treatment outcomes was possible by using SMD. Moreover, the limited age range of study participants in these trials (52-65 years) is relatively homogenous, with the majority being pre-retirement and postmenopausal. No variation was seen in acceptability of the interventions ${ }^{7}$. Moreover, to cost these studies, we employed validation checks and analysed different cost scenarios. Following this example, researchers could use our study to investigate cost implications in other countries; e.g. they could use Appendices 1-6 as a template for their context-specific care details and unit costs to perform their own micro-costing and obtain country-specific cost estimates.

\section{Limitations}

Nevertheless, limitations to this study exist. First, no accurate cost estimation per patient was available, which is a general difficulty with studies of this type ${ }^{55}$. We assessed incremental costs with or without depression treatment, i.e. we did not take cost savings due to improved cardiac outcomes into consideration that were previously shown in relation to effective depression treatment ${ }^{45,56}$. Additionally, there are potential implementation costs that we did not consider in our analysis. 
Accordingly, our study should be understood to provide a general direction only. Second, trial data stem from a range of countries, healthcare systems and time periods. Third, intervention duration and followup periods were restricted to 26 weeks, disabling investigation of longer-term outcomes. In particular exercise and psychotherapy potentially improve mental health and cardiac outcomes; longer follow-up periods would be needed to investigate this. Additionally, not all studies provided health state measurements exactly 8 and 26 weeks after inclusion ${ }^{7}$, but to ensure a consistent time perspective with the cost interval, we included reported health status results with these time points, which for some of the studies may differ within a few weeks. Fourth, an uneven number of trials was available for different interventions, e.g. only one trial investigated exercise. We did not investigate combination therapy due to high risk of bias in identified trials. No trial on group psychotherapy was included also, which is why we inferred effectiveness assumptions from individual psychotherapy trials. Notably, those providing 8week outcomes cumulatively indicate higher effectiveness within this short period of time than trials providing 26-week outcomes, most likely due to heterogeneity between trials. Overall, the evidence from trials was limited and subject to predominantly low risk of bias with some concerns; details are published in Doyle, Freedland ${ }^{7}$. Furthermore, remission provides a relatively narrow perspective and time to remission may be a comprehensive alternative outcome for original depression trials. These limitations are largely dictated by the structure and design of existing trials and should be considered in future trials. Last, we intended to estimate health system costs of all depression interventions alongside individual treatment costs; however we could not extrapolate costs to the Irish population as insufficient data on CAD and depression prevalence were available.

\section{Conclusion}

This study indicates that group exercise is the most cost-effective intervention for depression in individuals with CAD that shows within only 8 weeks of treatment. Pharmacotherapy also was costeffective after 8 or 26 weeks and may be considered as an alternative, in particular for patients who do not respond to exercise after 8 weeks. While individual psychotherapy was more expensive and less cost-effective, we suggest that group psychotherapy should be explored as a potentially cost-effective alternative to other depression treatments; however studies are needed to investigate the feasibility and effectiveness of group psychotherapy in Ireland as no trials on group psychotherapy were available. Where psychologists and cardiac physiologists are employed, cardiac rehabilitation programmes may offer an opportunity to integrate exercise early in CAD treatment to maximise efficiency. 


\section{Acknowledgements:}

We would like to thank Louise Enright and Kathleen Bennett in the RCSI University of Medicine and Health Sciences for their help with retrieving pharmaceutical unit prices.

\section{Conflict of interest:}

The authors have no conflict of interest to declare. 


\section{References}

1. Institute for Health Metrics and Evaluation. Ischemic heart disease - level 3 cause. http://www.healthdata.org/results/gbd summaries/2019/ischemic-heart-disease-level-3-cause (5/5/2021 2021).

2. Doyle F, McGee H, Conroy R, Conradi HJ, Meijer A, Steeds R, Sato H, Stewart DE, Parakh K, Carney R, Freedland K, Anselmino M, Pelletier R, Bos EH, de Jonge P. Systematic Review and Individual Patient Data Meta-Analysis of Sex Differences in Depression and Prognosis in Persons With Myocardial Infarction: A MINDMAPS Study. Psychosom Med 2015;77(4):419-28.

3. Burns A, Strawbridge JD, Clancy L, Doyle F. Exploring smoking, mental health and smokingrelated disease in a nationally representative sample of older adults in Ireland - A retrospective secondary analysis. J Psychosom Res 2017;98:78-86.

4. Carney RM, Freedland KE. Depression and coronary heart disease. Nat Rev Cardiol 2017;14(3):145-155.

5. Baumeister $\mathrm{H}$, Hutter N, Bengel J. Psychological and pharmacological interventions for depression in patients with coronary artery disease. Cochrane Database Syst Rev 2011(9):CD008012. 6. Richards SH, Anderson L, Jenkinson CE, Whalley B, Rees K, Davies P, Bennett P, Liu Z, West R, Thompson DR, Taylor RS. Psychological interventions for coronary heart disease. Cochrane Database Syst Rev 2017;4:CD002902.

7. Doyle F, Freedland KE, Carney RM, de Jonge P, Dickens C, Pedersen SS, Sorensen J, Dempster M. Hybrid Systematic Review and Network Meta-Analysis of Randomized Controlled Trials of Interventions for Depressive Symptoms in Patients With Coronary Artery Disease. Psychosom Med 2021;83(5):423431.

8. Doyle F, Freedland K, Carney R, de Jonge P, Dickens C, Pedersen S, Sorensen J, Dempster M. Network meta-analysis of randomised trials of pharmacological, psychotherapeutic, exercise and collaborative care interventions for depressive symptoms in patients with coronary artery disease: hybrid systematic review of systematic reviews protocol. Syst Rev 2019;8(1):71.

9. Archer J, Bower P, Gilbody S, Lovell K, Richards D, Gask L, Dickens C, Coventry P. Collaborative care for depression and anxiety problems. Cochrane Database Syst Rev 2012;10:CD006525.

10. Romeo R, Zala D, Knapp M, Orrell M, Fossey J, Ballard C. Improving the quality of life of care home residents with dementia: Cost-effectiveness of an optimized intervention for residents with clinically significant agitation in dementia. Alzheimers Dement 2019;15(2):282-291.

11. Smith DH, Johnson ES, Blough DK, Thorp ML, Yang X, Petrik AF, Crispell KA. Predicting costs of care in heart failure patients. BMC Health Serv Res 2012;12:434.

12. Duarte A, Walker J, Walker S, Richardson G, Holm Hansen C, Martin P, Murray G, Sculpher M, Sharpe M. Cost-effectiveness of integrated collaborative care for comorbid major depression in patients with cancer. J Psychosom Res 2015;79(6):465-70.

13. Aragones E, Sanchez-Iriso E, Lopez-Cortacans G, Tome-Pires C, Rambla C, Sanchez-Rodriguez E. Cost-effectiveness of a collaborative care program for managing major depression and chronic musculoskeletal pain in primary care: Economic evaluation alongside a randomized controlled trial. J Psychosom Res 2020;135:110167.

14. Stevenson MD, Scope A, Sutcliffe PA. The cost-effectiveness of group cognitive behavioral therapy compared with routine primary care for women with postnatal depression in the UK. Value Health 2010;13(5):580-4.

15. Stevenson MD, Scope A, Sutcliffe PA, Booth A, Slade P, Parry G, Saxon D, Kalthenthaler E, group cognitive behavioural therapy for postnatal depression advisory g. Group cognitive behavioural therapy for postnatal depression: a systematic review of clinical effectiveness, cost-effectiveness and value of information analyses. Health Technol Assess 2010;14(44):1-107, iii-iv. 
16. El Alaoui S, Hedman-Lagerlof E, Ljotsson B, Lindefors N. Does internet-based cognitive behaviour therapy reduce healthcare costs and resource use in treatment of social anxiety disorder? A costminimisation analysis conducted alongside a randomised controlled trial. BMJ Open 2017;7(9):e017053. 17. Keel G, Muhammad R, Savage C, Spaak J, Gonzalez I, Lindgren P, Guttmann C, Mazzocato P. Time-driven activity-based costing for patients with multiple chronic conditions: a mixed-method study to cost care in a multidisciplinary and integrated care delivery centre at a university-affiliated tertiary teaching hospital in Stockholm, Sweden. BMJ Open 2020;10(6):e032573.

18. Husereau D, Drummond M, Petrou S, Carswell C, Moher D, Greenberg D, Augustovski F, Briggs AH, Mauskopf J, Loder E, Force IHEEPG-CGRPT. Consolidated Health Economic Evaluation Reporting Standards (CHEERS)--explanation and elaboration: a report of the ISPOR Health Economic Evaluation Publication Guidelines Good Reporting Practices Task Force. Value Health 2013;16(2):231-50.

19. Špacírová Z, Epstein D, García-Mochón L, Rovira J, Olry de Labry Lima A, Espín J. A general framework for classifying costing methods for economic evaluation of health care. The European Journal of Health Economics 2020;21(4):529-542.

20. Health Service Executive. Pay scales. In; 2021.

21. Health Service Executive. HSE Organisational Structure. https://www.hse.ie/eng/about/who/ (30/4/2021 2021).

22. department of Public Expenditure and Reform. 2018 PUBLIC SERVICE SICK LEAVE STATISTICS AND TRENDS 2013 - 2018. In. Human Resource Management in the Civil Service; 2020.

23. Department of Public Expenditure and Reform. Civil Service Sick Leave Statistics 2018. In. Human Resource Management in the Civil Service; 2020.

24. Murphy A, Chu RW, Drummond FJ. A cost analysis of a community-based support centre for cancer patients and their families in Ireland: the EVeCANs study. Support Care Cancer 2021;29(2):619625.

25. Crosbie B, O'Callaghan ME, O'Flanagan S, Brennan D, Keane G, Behan W. A real-time measurement of general practice workload in the Republic of Ireland: a prospective study. Br J Gen Pract 2020;70(696):e489-e496.

26. Gibson J, Checkland K, Coleman A, Hann M, McCall R, Spooner S, Sutton M. Eighth National GP Worklife Survey. In. Manchester; 2015, 30.

27. Rosta J, Aasland OG. Doctors' working hours and time spent on patient care in the period 1994 2014. Tidsskr Nor Laegeforen 2016;136(16):1355-9.

28. Corcoran M, Byrne M. Evaluating a primary care psychology service in Ireland: a survey of stakeholders and psychologists. Health Soc Care Community 2017;25(3):1080-1089.

29. Nguyen HN, Sammer MB, Bales B, Cano MC, Trout AT, Dillman JR, Hayatghaibi SE. Time-Driven Activity-Based Cost Comparison of Three Imaging Pathways for Suspected Midgut Volvulus in Children. J Am Coll Radiol 2020;17(12):1563-1570.

30. Frasure-Smith N, Koszycki D, Swenson JR, Baker B, van Zyl LT, Laliberte MA, Abramson BL, Lambert J, Gravel G, Lesperance F. Design and rationale for a randomized, controlled trial of interpersonal psychotherapy and citalopram for depression in coronary artery disease (CREATE). Psychosom Med 2006;68(1):87-93.

31. Lesperance F, Frasure-Smith N, Koszycki D, Laliberte MA, van Zyl LT, Baker B, Swenson JR, Ghatavi K, Abramson BL, Dorian P, Guertin MC, Investigators C. Effects of citalopram and interpersonal psychotherapy on depression in patients with coronary artery disease: the Canadian Cardiac Randomized Evaluation of Antidepressant and Psychotherapy Efficacy (CREATE) trial. JAMA 2007;297(4):367-79.

32. Blumenthal JA, Sherwood A, Babyak MA, Watkins LL, Smith PJ, Hoffman BM, O'Hayer CV, Mabe $\mathrm{S}$, Johnson J, Doraiswamy PM, Jiang W, Schocken DD, Hinderliter AL. Exercise and pharmacological treatment of depressive symptoms in patients with coronary heart disease: results from the UPBEAT 
(Understanding the Prognostic Benefits of Exercise and Antidepressant Therapy) study. J Am Coll Cardiol 2012;60(12):1053-63.

33. Kim JM, Stewart R, Lee YS, Lee HJ, Kim MC, Kim JW, Kang HJ, Bae KY, Kim SW, Shin IS, Hong YJ, Kim JH, Ahn Y, Jeong MH, Yoon JS. Effect of Escitalopram vs Placebo Treatment for Depression on Longterm Cardiac Outcomes in Patients With Acute Coronary Syndrome: A Randomized Clinical Trial. JAMA 2018;320(4):350-358.

34. Freedland KE, Skala JA, Carney RM, Rubin EH, Lustman PJ, Davila-Roman VG, Steinmeyer BC, Hogue CW, Jr. Treatment of depression after coronary artery bypass surgery: a randomized controlled trial. Arch Gen Psychiatry 2009;66(4):387-96.

35. Berkman LF, Blumenthal J, Burg M, Carney RM, Catellier D, Cowan MJ, Czajkowski SM, DeBusk R, Hosking J, Jaffe A, Kaufmann PG, Mitchell P, Norman J, Powell LH, Raczynski JM, Schneiderman N, Enhancing Recovery in Coronary Heart Disease Patients I. Effects of treating depression and low perceived social support on clinical events after myocardial infarction: the Enhancing Recovery in Coronary Heart Disease Patients (ENRICHD) Randomized Trial. JAMA 2003;289(23):3106-16.

36. Enhancing recovery in coronary heart disease patients (ENRICHD): study design and methods. The ENRICHD investigators. Am Heart J 2000;139(1 Pt 1):1-9.

37. Cuijpers $P$, Noma H, Karyotaki E, Cipriani A, Furukawa TA. Effectiveness and Acceptability of Cognitive Behavior Therapy Delivery Formats in Adults With Depression: A Network Meta-analysis. JAMA Psychiatry 2019;76(7):700-707.

38. Davidson KW, Bigger JT, Burg MM, Carney RM, Chaplin WF, Czajkowski S, Dornelas E, DuerHefele J, Frasure-Smith N, Freedland KE, Haas DC, Jaffe AS, Ladapo JA, Lesperance F, Medina V, Newman JD, Osorio GA, Parsons F, Schwartz JE, Shaffer JA, Shapiro PA, Sheps DS, Vaccarino V, Whang W, Ye S. Centralized, stepped, patient preference-based treatment for patients with post-acute coronary syndrome depression: CODIACS vanguard randomized controlled trial. JAMA Intern Med 2013;173(11):997-1004.

39. Whang W, Burg MM, Carney RM, Freedland KE, Bigger JT, Catellier D, Czajkowski S, FrasureSmith N, Haas DC, Jaffe AS, Lesperance F, Medina V, Duer-Hefele J, Osorio GA, Parsons F, Shapiro PA, Sheps DS, Vaccarino V, Davidson KW. Design and baseline data from the vanguard of the Comparison of Depression Interventions after Acute Coronary Syndrome (CODIACS) randomized controlled trial. Contemp Clin Trials 2012;33(5):1003-10.

40. Carney RM, Freedland KE, Steinmeyer BC, Rubin EH, Ewald G. Collaborative care for depression symptoms in an outpatient cardiology setting: A randomized clinical trial. Int J Cardiol 2016;219:164-71. 41. Irish Association of Cardiac Rehabilitation. Cardiac Rehabilitation Guidelines. In; 2013.

42. Magnusson K. Interpreting Cohen's d Effect Size: An Interactive Visualization. In; 2021.

43. Kolovos S, Finch AP, van der Ploeg HP, van Nassau F, Broulikova HM, Baka A, Treweek S, Gray CM, Jelsma JGM, Bunn C, Roberts GC, Silva MN, Gill JMR, Røynesdal $\varnothing$, van Mechelen W, Andersen E, Hunt K, Wyke S, Bosmans JE. Five-year cost-effectiveness analysis of the European Fans in Training (EuroFIT) physical activity intervention for men versus no intervention. International Journal of Behavioral Nutrition and Physical Activity 2020;17(1):30.

44. Santiago de Araujo Pio C, Marzolini S, Pakosh M, Grace SL. Effect of Cardiac Rehabilitation Dose on Mortality and Morbidity: A Systematic Review and Meta-regression Analysis. Mayo Clin Proc 2017;92(11):1644-1659.

45. Ladapo JA, Shaffer JA, Fang Y, Ye S, Davidson KW. Cost-effectiveness of Enhanced Depression Care After Acute Coronary Syndrome: Results From the Coronary Psychosocial Evaluation Studies Randomized Controlled Trial. Archives of Internal Medicine 2012;172(21):1682-1684.

46. Celano CM, Healy B, Suarez L, Levy DE, Mastromauro C, Januzzi JL, Huffman JC. CostEffectiveness of a Collaborative Care Depression and Anxiety Treatment Program in Patients with Acute Cardiac Illness. Value Health 2016;19(2):185-91. 
47. Donohue JM, Belnap BH, Men A, He F, Roberts MS, Schulberg HC, Reynolds CF, 3rd, Rollman BL. Twelve-month cost-effectiveness of telephone-delivered collaborative care for treating depression following CABG surgery: a randomized controlled trial. Gen Hosp Psychiatry 2014;36(5):453-9.

48. Camacho EM, Davies LM, Hann M, Small N, Bower P, Chew-Graham C, Baguely C, Gask L, Dickens CM, Lovell K, Waheed W, Gibbons CJ, Coventry P. Long-term clinical and cost-effectiveness of collaborative care (versus usual care) for people with mental-physical multimorbidity: clusterrandomised trial. Br J Psychiatry 2018;213(2):456-463.

49. Maddison R, Rawstorn JC, Stewart RAH, Benatar J, Whittaker R, Rolleston A, Jiang Y, Gao L, Moodie M, Warren I, Meads A, Gant N. Effects and costs of real-time cardiac telerehabilitation: randomised controlled non-inferiority trial. Heart 2019;105(2):122-129.

50. Health Service Executive. Chronic Disease Management Programme. https://www.hse.ie/eng/about/who/gmscontracts/2019agreement/chronic-disease-managementprogramme/ (27/9/2021).

51. Price KJ, Gordon BA, Bird SR, Benson AC. A review of guidelines for cardiac rehabilitation exercise programmes: Is there an international consensus? Eur J Prev Cardiol 2016;23(16):1715-1733.

52. Gallagher J. Cardiac Rehabilitation in the Modern Era of Cardiology. Hospital Professional News Ireland 2021.

53. Blumenthal JA, Sherwood A, Smith PJ, Watkins L, Mabe S, Kraus WE, Ingle K, Miller P, Hinderliter A. Enhancing Cardiac Rehabilitation With Stress Management Training: A Randomized, Clinical Efficacy Trial. Circulation 2016;133(14):1341-50.

54. Pio CSA, Chaves G, Davies P, Taylor R, Grace S. Interventions to Promote Patient Utilization of Cardiac Rehabilitation: Cochrane Systematic Review and Meta-Analysis. J Clin Med 2019;8(2).

55. Shearer J, McCrone P, Romeo R. Economic Evaluation of Mental Health Interventions: A Guide to Costing Approaches. Pharmacoeconomics 2016;34(7):651-64.

56. Bangalore S, Shah R, Gao X, Pappadopulos E, Deshpande CG, Shelbaya A, Prieto R, Stephens J, Chambers R, Schepman P, McIntyre RS. Economic burden associated with inadequate antidepressant medication management among patients with depression and known cardiovascular diseases: insights from a United States-based retrospective claims database analysis. J Med Econ 2020;23(3):262-270. 
Tables

Table 1: Incremental intervention costs after 8 and 26 weeks compared to usual care (cost per patient)

\begin{tabular}{cccc}
\hline Intervention & Cost in $€$ 8 weeks & Cost in $€$ weeks 9-26 & Total 26-week cost in $€$ : \\
\hline Pharmacotherapy & 215.66 & 120.22 & 335.88 \\
\hline LCS & 199.94 & 51.67 & 251.62 \\
\hline HCS & 169.32 & 208.14 & 377.46 \\
\hline Individual psychotherapy & $\mathbf{4 4 8 . 4 3}$ & $\mathbf{1 4 9 . 4 8}$ & $\mathbf{5 9 7 . 9 1}$ \\
\hline HCS & 605.83 & 346.19 & 952.02 \\
\hline SA: Groups of 6 patients & 74.74 & 24.91 & 99.65 \\
\hline Collaborative care & 501.43 & 327.47 & 828.91 \\
\hline HCS & 588.07 & 407.12 & 995.19 \\
\hline Group exercise (5 patients ${ }^{*}$ ) & $\mathbf{2 0 1 . 6 5}$ & $\mathbf{1 8 3 . 9 3}$ & $\mathbf{3 8 5 . 5 8}$ \\
\hline SA: Individual exercise & 937.38 & 919.67 & $1,857.05$ \\
\hline
\end{tabular}

Notes: $\mathrm{HCS}=$ high-cost scenario; $\mathrm{LCS}=$ low-cost scenario - note that the low-cost assumptions relate to the total 26-week treatment period and only occur higher in the 8-week cost, but not in total; SA = sensitivity analysis (in italics);

* 5:1 ratio of treadmill users and supervising staff is recommended in Irish cardiac rehab guidelines;

$\ddagger 9$-26 weeks or latest available 
Table 2: Effectiveness and incremental cost-effectiveness of interventions compared to usual care

\begin{tabular}{|c|c|c|c|c|}
\hline \multirow[t]{2}{*}{ Intervention } & \multicolumn{2}{|c|}{$\begin{array}{l}\text { Number needed to treat per } \\
\text { patient in remission* }\end{array}$} & \multicolumn{2}{|c|}{ Incremental cost per remission in $€$} \\
\hline & 8 weeks & 26 weeks & 8 weeks & 26 weeks \\
\hline Pharmacotherapy & 3.5 & 1.8 & 750.50 & 591.15 \\
\hline LCS & $=$ & $=$ & 695.80 & 442.84 \\
\hline $\mathrm{HCS}$ & $=$ & $=$ & 589.25 & 664.33 \\
\hline Individual psychotherapy & 7.0 & 15.7 & 3116.58 & 9387.12 \\
\hline HCS & $=$ & $=$ & 4210.53 & 14946.74 \\
\hline SA: Groups of 6 patients & $=$ & $=$ & 519.43 & 1564.52 \\
\hline Collaborative care & 9.9 & 8.7 & 4964.21 & 7203.19 \\
\hline HCS & $=$ & $=$ & 5821.87 & 8648.22 \\
\hline Group exercise (5 patients) & 2.6 & N/A & 526.30 & $\mathrm{~N} / \mathrm{A}$ \\
\hline SA: individual exercise & $=$ & $=$ & 2446.57 & $N / A$ \\
\hline
\end{tabular}

Notes: $\mathrm{HCS}=$ high-cost scenario; $\mathrm{LCS}=$ low-cost scenario - note that the low-cost assumptions relate to the total 26-week treatment period and only occur higher in the 8-week cost, but not in total; SA= sensitivity analysis (in italics);

* based on network meta-analysis 